\title{
$\begin{array}{ll}\text { Research Square } & \begin{array}{l}\text { Preprints are preliminary reports that have not undergone peer review. } \\ \text { They should not be considered conclusive, used to inform clinical practice, } \\ \text { or referenced by the media as validated information. }\end{array}\end{array}$
}

\section{Bone Metastasis is Uncommon in Patients with Oral Squamous Cell Carcinoma at Diagnosis-Bone Scan may be Not Necessary for Staging}

\section{Cheng-Ping Wang}

National Taiwan University Hospital and National Taiwan University College of Medicine

Wan-Lun Hsu

Academia Sinica

Pei-Jen Lou

National Taiwan University Hospital and National Taiwan University College of Medicine Jenq-Yuh Ko

National Taiwan University Hospital and National Taiwan University College of Medicine

Tseng-Cheng Chen ( $\nabla$ tcchen0102@ntu.edu.tw)

National Taiwan University Hospital and National Taiwan University College of Medicine

\section{Research Article}

Keywords: oral cancer, bone metastasis, bone scan, distant metastasis, staging

Posted Date: July 14th, 2021

DOI: https://doi.org/10.21203/rs.3.rs-702900/v1

License: (c) (i) This work is licensed under a Creative Commons Attribution 4.0 International License. Read Full License 


\section{Abstract}

Only a small portion of the patients with oral squamous cell carcinoma (OSCC) experience bone metastasis. This study is to evaluate the percentage of bone metastasis at diagnosis and after treatment and to discuss whether bone scan is necessary in OSCC patients. The medical records of all patients with newly diagnosed OSCC receiving bone scan or positron emission tomography (PET) at diagnosis between 2010 and 2015 were retrospectively reviewed. A total of 1049 patients were enrolled, including 458 (44\%) with early stage tumor and 591 (56\%) with late stage tumor. In total, $33(3.1 \%)$ patients had bone metastasis at diagnosis ( 9 patients, $0.86 \%$ ) and after treatment (24 patients, $2.29 \%$ ) during the mean follow-up of 12 months. Among those with subsequent bone metastasis, only 5 (21\%) patients had bone-only metastasis. All patients with bone metastasis before primary treatment and all but two patients with bone metastasis after treatment had locoregionally advanced OSCC. The mean survival time of the 33 patients after diagnosis of bone metastasis was 121 days. Bone metastasis is uncommon in patients with OSCC. It is not necessary to routinely use bone scan for initial staging, especially early stage OSCC, and for follow-up.

\section{Introduction}

Oral squamous cell carcinoma (OSCC) is one of the most common malignancies in the world, nearly 40,000 newly diagnosed each year. ${ }^{1-3}$ In Taiwan, the age-adjusted incidence rates of OSCC are still increasing in the past decades and reaching the plateau around 2010's. ${ }^{3,4}$ OSCC is the sixth common cancer and the fifth cancer cause of death in 2018. 3,4 The standard treatment of OSCC is surgery with or without postoperative adjuvant chemoradiation, providing a better 5-year overall survival rate of approximately $50-70 \%$, compared with other primary modalities of treatment. ${ }^{1-3,5}$ The major determinants of surgery for OSCC are tumor stage and the patient's general condition. ${ }^{5}$ It is general accepted that radical surgery is not the first choice when the OSCC patient has distant metastasis at diagnosis. ${ }^{6}$ Therefore, it is very important to make sure that there is no distant metastasis before radical surgery.

Distant metastasis of OSCC is not common at diagnosis, compared with other head and neck cancers. ${ }^{7-}$ ${ }^{13}$ The lung is the most common site of distant metastasis and bone metastasis is less common among OSCC patients. ${ }^{7-13}$ Bone scan is the most common and cheap imaging study for bone metastasis, however it has a radiation dose, which is classified as WHO category III, making routinely regular examination potentially harmful to the OSCC patient and medical staff by second-hand radiation so that its use in routine staging process or regular follow-up of OSCC is needed to be justified. ${ }^{14}$ Although National Cancer Comprehensive Network (NCCN) guideline doesn't mention bone scan as a standard work-up for OSCC at diagnosis, ${ }^{6}$ bone scan is still regularly performed for initial staging in many places. Therefore, the aim of our study is to investigate the prevalence of bone metastasis of OSCC at diagnosis and after treatment, to identify the high risk group for bone metastasis and to discuss whether bone scan is necessary as an imaging study for initial staging and regular follow-up of OSCC. 


\section{Results}

Among 1219 patients were diagnosed newly diagnosed OSCC between 2010 and 2015, 1049 patients received bone scan or PET for initial stage at diagnosis. The Table 1 showed the comparison of clinical characteristics between 1049 patients receiving bone metastasis study at diagnosis and 170 patients not. The age of the patients with bone study at diagnosis was significantly younger than that without bone study $(p=0.038)$. T classification, $\mathrm{N}$ classification and initial overall stage were significantly more advanced in the patients receiving bone study at diagnosis $(p<0.01)$. Among 1049 patients including 458 (44\%) with early stage tumor and 591 (56\%) with late stage tumor, only $9(0.86 \%)$ patients had bone metastasis at diagnosis. The age of the patients ranges from 34 to 64 years old, with an average of 51 years old. The primary tumor location was the buccal mucosa in 4 patients, tongue in 2 patients, lower gum in 2 patients and mouth floor in one patient. All patients had locoregionally advanced diseases (stage III-IV). During the follow-up time of one month to 91 months with a mean of 34 months after treatment of all 1049 patients, another 24 (2.3\%) patients had distant bone metastasis developed 2 months to 43 months after primary treatment, with an average of 12 months. The age of the patients ranges from 32 to 76 years old, with an average of 54 years old. The primary tumor location was the buccal mucosa in 5 patients, tongue in 11 patients, lower gum in 3 patients, retromolar trigone in 2 patients, hard palate in 2 patients and lower lip in one patient. Nineteen (79\%) patients had locoregional recurrences or other distant metastasis at the same time or before bone metastasis was noted. Only 5 (21\%) patients had bone-only metastasis. All but two patients with T1N0 and T2N0 disease had locoregionally advanced diseases (stage III in 3 patients and stage IV in 19 patients) at initial diagnosis. In total, 33 (3.1\%) patients had bone metastasis. The Table 2 showed clinical characteristics of these patients with bone metastasis. The mean survival time of the 33 patients after diagnosis of bone metastasis was 121 days with a range from 0 day to 365 days. Only two $(1.18 \%)$ patients in the patients without bone study at diagnosis had subsequent bone metastasis and both had locoregionally advanced disease at initial diagnosis. 
Table 1

The clinical characteristics of the 1219 patients with newly diagnosed OSCC between 2010 and 2015 .

\begin{tabular}{|c|c|c|c|}
\hline & $\begin{array}{l}\text { Patients with initial bone study } \\
(n=1049)\end{array}$ & $\begin{array}{l}\text { Patients without initial bone study } \\
(n=170)\end{array}$ & $\begin{array}{l}P \\
\text { value }\end{array}$ \\
\hline $\begin{array}{l}\text { Age, years, mean } \\
\text { (range) }\end{array}$ & $54(21-89)$ & $56(22-88)$ & 0.038 \\
\hline Gender, M: F & $941: 108$ & 146: 14 & 0.55 \\
\hline Tumor location & & & 0.05 \\
\hline Buccal mucosa & 338 (32\%) & $51(30 \%)$ & \\
\hline Tongue & $404(39 \%)$ & $69(41 \%)$ & \\
\hline Gum & $141(13 \%)$ & $21(12 \%)$ & \\
\hline Mouth floor & $47(5 \%)$ & $4(2 \%)$ & \\
\hline Retromolar trigone & $41(4 \%)$ & $9(5 \%)$ & \\
\hline Palate & $53(5 \%)$ & $5(3 \%)$ & \\
\hline Lip & $25(2 \%)$ & $11(7 \%)$ & \\
\hline $\begin{array}{l}\text { Tumor } \\
\text { differentiation }\end{array}$ & & & 0.38 \\
\hline Well differentiation & $540(52 \%)$ & 95 (56\%) & \\
\hline $\begin{array}{l}\text { Moderate } \\
\text { differentiation }\end{array}$ & 481 (45\%) & $73(43 \%)$ & \\
\hline $\begin{array}{l}\text { Poor } \\
\text { differentiation }\end{array}$ & $28(3 \%)$ & $2(1 \%)$ & \\
\hline T classification & & & $\begin{array}{l}< \\
0.01\end{array}$ \\
\hline T1 & 337 (32\%) & $98(53 \%)$ & \\
\hline T2 & 300 (29\%) & $39(23 \%)$ & \\
\hline T3 & $81(8 \%)$ & $5(3 \%)$ & \\
\hline $\mathrm{T} 4$ & 331 (31\%) & $28(16 \%)$ & \\
\hline $\mathrm{N}$ classification & & & $\begin{array}{l}<.01 \\
0.01\end{array}$ \\
\hline No & $653(62 \%)$ & 147 (87\%) & \\
\hline N1 & $123(12 \%)$ & $11(6 \%)$ & \\
\hline N2 & $260(25 \%)$ & $11(6 \%)$ & \\
\hline
\end{tabular}




\begin{tabular}{|llll|}
\hline & $\begin{array}{l}\text { Patients with initial bone study } \\
(\mathbf{n = 1 0 4 9 )}\end{array}$ & $\begin{array}{l}\text { Patients without initial bone study } \\
(\mathbf{n = 1 7 0 )}\end{array}$ & $\begin{array}{l}\text { P } \\
\text { value }\end{array}$ \\
\hline N3 & $13(1 \%)$ & $1(1 \%)$ & \\
\hline Stage & & & \\
\hline I & $282(27 \%)$ & $89(52 \%)$ \\
\hline II & $176(17 \%)$ & $33(20 \%)$ \\
\hline III & $145(14 \%)$ & $14(8 \%)$ \\
\hline IV & $446(42 \%)$ & $34(20 \%)$ \\
\hline Bone metastasis & & \\
\hline At diagnosis & $9(0.86 \%)$ & - \\
\hline After treatment & $24(2.29 \%)$ & $2(1.18 \%)$ \\
\hline
\end{tabular}


Table 2

The clinical characteristics of the 33 OSCC patients with bone metastasis at diagnosis and during subsequent follow-up.

\begin{tabular}{|c|c|c|}
\hline & $\begin{array}{l}\text { Bone metastasis at } \\
\text { diagnosis }(n=9)\end{array}$ & $\begin{array}{l}\text { Bone metastasis during follow- } \\
\text { up }(n=24)\end{array}$ \\
\hline Age, years, mean (range) & $51(34-64)$ & $54(32-76)$ \\
\hline Gender, M: F & $8: 1$ & $23: 1$ \\
\hline \multicolumn{3}{|l|}{ Tumor location } \\
\hline Buccal mucosa & $4(45 \%)$ & $5(21 \%)$ \\
\hline Tongue & $2(22 \%)$ & $11(46 \%)$ \\
\hline Gum & $2(22 \%)$ & $3(43 \%)$ \\
\hline Mouth floor & $1(11 \%)$ & 0 \\
\hline Retromolar trigone & 0 & $2(8 \%)$ \\
\hline Palate & 0 & $2(8 \%)$ \\
\hline Lip & 0 & $1(4 \%)$ \\
\hline \multicolumn{3}{|l|}{ Tumor differentiation } \\
\hline Well differentiation & $5(56 \%)$ & $10(42 \%)$ \\
\hline Moderate differentiation & $4(44 \%)$ & $11(46 \%)$ \\
\hline Poor differentiation & 0 & $3(12 \%)$ \\
\hline \multicolumn{3}{|l|}{ T classification } \\
\hline T1 & $1(11 \%)$ & $2(8 \%)$ \\
\hline $\mathrm{T} 2$ & $1(11 \%)$ & $6(25 \%)$ \\
\hline T3 & $1(11 \%)$ & $3(13 \%)$ \\
\hline $\mathrm{T} 4$ & $6(67 \%)$ & $13(54 \%)$ \\
\hline \multicolumn{3}{|l|}{$\mathrm{N}$ classification } \\
\hline NO & 0 & $5(21 \%)$ \\
\hline N1 & $2(22 \%)$ & $5(21 \%)$ \\
\hline $\mathrm{N} 2 \mathrm{~b}$ & $4(44 \%)$ & $11(46 \%)$ \\
\hline N2c & $3(33 \%)$ & $2(8 \%)$ \\
\hline N3 & 0 & $1(4 \%)$ \\
\hline
\end{tabular}




\begin{tabular}{|lll|}
\hline & $\begin{array}{l}\text { Bone metastasis at } \\
\text { diagnosis }(\mathbf{n = 9 )}\end{array}$ & $\begin{array}{l}\text { Bone metastasis during follow- } \\
\text { up }(\mathbf{n = 2 4})\end{array}$ \\
\hline Early primary and neck (T1-2N0) & 0 & $2(8 \%)$ \\
\hline $\begin{array}{l}\text { Late primary and neck (more } \\
\text { than T1-2N0) }\end{array}$ & $9(100 \%)$ & $22(92 \%)$ \\
\hline
\end{tabular}

\section{Discussion}

In comparison with other head and neck cancers, distant metastasis is less common in OSCC, with 1.8 to $15 \%$, especially at time of diagnosis. ${ }^{7-13}$ The lung is the most common site of distant metastasis so the imaging study of the chest is generally recommended for lung metastasis. ${ }^{7-13}$ Distant bone metastasis is much less common than lung metastasis in OSCC patients. ${ }^{7-13}$ In a large population-based study in USA, only $1.8 \%$ of OSCC patients had distant metastasis and only $0.53 \%$ of patients had bone metastasis at diagnosis. ${ }^{12}$ In our relatively large hospital-based cohort, only $0.85 \%$ of OSCC had distant bone metastasis at diagnosis and the other $2.3 \%$ of the patients had bone metastasis during the follow-up after primary treatment. Therefore, it raises a question that bone scan may be not necessary for initial staging process and follow-up in a regular manner.

Bone scan is a radioisotope imaging study to mainly detect osteoblastic activity. It is a highly sensitive diagnostic imaging to detect bone metastasis, but a positive result is frequently nonspecific. ${ }^{13-15}$ For other cancers with frequent bone metastasis, for example, breast cancer, prostate cancer and lung cancer, bone scan may be cost-effective to detect bone metastasis. ${ }^{14,16}$ However, bone scan has a lower positive predictive value for bone metastasis of OSCC because of low specificity and low prevalence at diagnosis and after treatment. ${ }^{13,15}$ It is usually necessary to do other imaging studies such as MRI, PET/CT, which is usually done for late stage OSCC, to exclude non-specific findings. ${ }^{14}$ Secondly, the majority of bone metastases from OSCC is osteolytic process, causing more symptomatic, which is very indicative. Therefore, most recent studies suggested that routine use of bone scan for bone metastasis of OSCC was not necessary. ${ }^{11-13}$ NCCN guideline recommends work-up for distant bone metastasis "as clinically indicated" for OSCC, either at diagnosis or follow-up. ${ }^{6}$ Furthermore, bone metastasis rarely occurs in absence of other distant metastasis or recent locoregional recurrence and most patients with bone metastasis had locoregionally advanced tumor at time of diagnosis according to the previous literature and this series, $7,11-13$ PET/CT scan may be more comprehensive, sensitive and specific for evaluation of the tumor extent as NCCN guideline recommends, especially for detection of extrapulmonary metastasis and occult second primary cancer. $6,12,16-18$ The functional data from PET/CT is also helpful for the evaluation of suspicious contralateral lymph node metastasis and probably helpful for radiation planning ${ }^{12}$, and maybe imply the tumor aggressiveness. ${ }^{19}$

Although bone scan was considered as an imaging tool for evaluating local facial bone invasion at the primary site ${ }^{15,20}$, bone management during surgery including the maxilla and mandible may not be 
appropriate based on bone scan because it is too sensitive with a high false positive result. MRI and PET/CT have been reported to be more accurate to predict bone cortex and marrow invasion by adjacent OSCC, which are more helpful for surgical planning. ${ }^{21}$ Therefore, it may not be justified to routinely use bone scan to evaluate the maxilla and mandible invasion of OSCC.

If bone scan is still considered as a staging process at diagnosis and follow-up because of some reasons, it should be limited to the typical symptoms indicative of bone metastasis, the patients with locoregionally advanced OSCC, especially T4, contralateral nodal or N3 disease, or poorly differentiated tumor, which have a higher risk for distant bone metastasis. ${ }^{7,8,12,21}$

In conclusion, distant bone metastasis is uncommon in patients with OSCC. It is not necessary to routinely use bone scan for initial staging, especially early stage OSCC, and for follow-up.

\section{Methods}

Medical records and radiological reports of the patients who were diagnosed with newly diagnosed OSCC at the National Taiwan University Hospital between January 2010 and December 2015 were retrospectively reviewed. The study was reviewed and approved by the institutional review board of the National Taiwan University Hospital. Written informed consent was obtained from all patients and/or their legal guardians. All methods were performed in accordance with the relevant guidelines and regulations. Patients with previous primary head and neck cancer, primary head and neck cancer other than SCC, the presence of a simultaneous second primary cancer or malignancies outside the head and neck regions were excluded from this study. Patients who had no bone scan or positron emission tomography (PET) at diagnosis of OSCC were also excluded. All patients received routine staging examination (head and neck Magnetic Resonance Imaging (MRI), chest plain film/chest Computerized Tomography (CT) scan for lung metastasis, liver ultrasound for liver metastasis and bone scan or PET) to determine the initial stage of OSCC. If bone scan showed suspicious bone metastasis, CT or MRI of the bone lesion or PET were done to confirm the metastatic lesion. The head and neck surgeons, medical oncologists, and radiation oncologists meet regularly in the tumor board to review the stage and suggest the treatment choice, especially for late stage OSCC. The primary treatment of OSCC was wide excision of the primary oral tumor with/without ipsilateral/bilateral neck dissection when the tumor was still resectable and the patient was tolerable to surgery. Post-operative chemoradiation or radiation was given based on the clinical and pathological risk factors according to NCCN guidelines in general. ${ }^{6}$ Regarding the follow-up of locoregional status and distant metastasis after treatment, MRI or CT scan of the head and neck was done 3 months after complete treatment for every patient and every 6-24 months or as clinically indicated after that, Chest plain film and blood biochemistry test were regularly performed every 6 to 12 months. Regarding subsequent bone metastasis, bone scan or PET scan was performed when persistent bone pain was present or when locoregional recurrence or other distant metastasis was diagnosed. Bone metastasis is defined as distant bone metastasis, excluding the craniofacial bone adjacent to the primary or neck tumor. 
The initial TNM stage was classified according to the 2010 criteria of the American Joint Committee on Cancer (AJCC) ${ }^{22}$ Fisher's exact test and chi-square test were used to determine the differences of clinical characteristics of the patients between with and without imaging study for bone metastasis at diagnosis, including age, sex, primary tumor location, $\mathrm{T}$ classification, $\mathrm{N}$ classification, overall stage and tumor differentiation. The starting point of the follow-up period was defined as the time since completion of the primary treatment for each patient. The endpoint of the follow-up was defined as the time when the patient died or December 2018. All patients received follow-up examination for $\geq 24$ months or until death after primary definitive treatment. A p-value $<0.05$ was considered statistically significant.

\section{Declarations}

Cheng-Ping Wang and Tseng-Cheng Chen wrote the main manuscript; Wan-Lun Hsu, Pei-Jen Lou, and Jenq-Yuh Ko completed data analyses and prepared tables 1-2. All authors reviewed the manuscript.

\section{Competing interests}

The authors declare no competing interests.

\section{References}

1. Ferlay, J. et al. Estimating the global cancer incidence and mortality in 2018: GLOBOCAN sources and methods. Int J Cancer 144, 1941-1953, doi:10.1002/ijc.31937 (2019).

2. Duprez, F. et al. Distant metastases in head and neck cancer. Head Neck, 39, 1733-1743 https://doi.org/10.1002/hed.24687 (2017).

3. Liu, J. C., Bhayani, M., Kuchta, K., Galloway, T. \& Fundakowski, C. Patterns of distant metastasis in head and neck cancer at presentation: Implications for initial evaluation. Oral Oncol, 88, 131-136 https://doi.org/10.1016/j.oraloncology.2018.11.023 (2019).

4. Ferlito, A., Buckley, J. G., Rinaldo, A. \& Mondin, V. Screening tests to evaluate distant metastases in head and neck cancer. ORL J Otorhinolaryngol Relat Spec, 63, 208-211 https://doi.org/10.1159/000055741 (2001).

5. Van den Wyngaert, T. et al. The EANM practice guidelines for bone scintigraphy. Eur J Nucl Med Mol Imaging, 43, 1723-1738 https://doi.org/10.1007/s00259-016-3415-4 (2016).

6. Onizawa, K. \& Yoshida, H. Evaluation of $67 \mathrm{Ga}$ citrate and $99 \mathrm{~m}$ Tc bone scintigraphy at initial examination for primary oral squamous cell carcinoma. J Oral Maxillofac Surg, 61, 913-917 https://doi.org/10.1016/s0278-2391(03)00291-x (2003).

7. Krabbe, C. A., Pruim, J., van der Laan, B. F., Rödiger, L. A. \& Roodenburg, J. L. FDG-PET and detection of distant metastases and simultaneous tumors in head and neck squamous cell carcinoma: a comparison with chest radiography and chest CT. Oral Oncol, 45, 234-240 https://doi.org/10.1016/j.oraloncology.2008.05.024 (2009). 
8. Rohde, M. et al. Head-to-Head Comparison of Chest X-Ray/Head and Neck CT/Head and Neck MRI, and (18)F-FDG PET/CT for Detection of Distant Metastases and Synchronous Cancer in Oral, Pharyngeal, and Laryngeal Cancer. J Nucl Med 58, 1919-1924, doi:10.2967/jnumed.117.189704 (2017).

9. Chan, S. C. et al. Utility of 18F-fluoride PET/CT and 18F-FDG PET/CT in the detection of bony metastases in heightened-risk head and neck cancer patients. J Nucl Med, 53, 1730-1735 https://doi.org/10.2967/jnumed.112.104893 (2012).

10. Liao, C. T. et al. A combined analysis of maximum standardized uptake value on FDG-PET, genetic markers, and clinicopathological risk factors in the prognostic stratification of patients with resected oral cavity squamous cell carcinoma. Eur J Nucl Med Mol Imaging, 47, 84-93 https://doi.org/10.1007/s00259-019-04453-x (2020).

11. Fischer-Brandies, E. \& Seifert, C. Bone scintigraphy: an aid in deciding on the extent of bone resection in malignant oral tumors. J Oral Maxillofac Surg, 53, 768-770 https://doi.org/10.1016/02782391(95)90328-3 (1995).

12. Abd El-Hafez, Y. G. et al. Comparison of PET/CT and MRI for the detection of bone marrow invasion in patients with squamous cell carcinoma of the oral cavity. Oral Oncol, 47, 288-295 https://doi.org/10.1016/j.oraloncology.2011.02.010 (2011).

13. Edge, S. B. \& Compton, C. C. The American Joint Committee on Cancer: the 7th edition of the AJCC cancer staging manual and the future of TNM. Ann Surg Oncol, 17, 1471-1474 https://doi.org/10.1245/s10434-010-0985-4 (2010).

14. Cheng-Ping Wang and Tseng-Cheng Chen wrote the main manuscript; Wan-Lun Hsu, Pei-Jen Lou, and Jenq-Yuh Ko completed data analyses and prepared tables 1-2. All authors reviewed the manuscript.

15. Onizawa, K. \& Yoshida, H. Evaluation of $67 \mathrm{Ga}$ citrate and $99 \mathrm{~m}$ Tc bone scintigraphy at initial examination for primary oral squamous cell carcinoma. J Oral Maxillofac Surg 61, 913-917, doi:10.1016/s0278-2391(03)00291-x (2003).

16. Krabbe, C. A., Pruim, J., van der Laan, B. F., Rödiger, L. A. \& Roodenburg, J. L. FDG-PET and detection of distant metastases and simultaneous tumors in head and neck squamous cell carcinoma: a comparison with chest radiography and chest CT. Oral Oncol 45, 234-240, doi:10.1016/j.oraloncology.2008.05.024 (2009).

17. Rohde, M. et al. Head-to-Head Comparison of Chest X-Ray/Head and Neck MRI, Chest CT/Head and Neck MRI, and (18)F-FDG PET/CT for Detection of Distant Metastases and Synchronous Cancer in Oral, Pharyngeal, and Laryngeal Cancer. J Nucl Med 58, 1919-1924, doi:10.2967/jnumed.117.189704 (2017).

18. Chan, S. C. et al. Utility of 18F-fluoride PET/CT and 18F-FDG PET/CT in the detection of bony metastases in heightened-risk head and neck cancer patients. J Nucl Med 53, 1730-1735, doi:10.2967/jnumed.112.104893 (2012). 
19. Liao, C. T. et al. A combined analysis of maximum standardized uptake value on FDG-PET, genetic markers, and clinicopathological risk factors in the prognostic stratification of patients with resected oral cavity squamous cell carcinoma. Eur J Nucl Med Mol Imaging 47, 84-93, doi:10.1007/s00259019-04453-x (2020).

20. Fischer-Brandies, E. \& Seifert, C. Bone scintigraphy: an aid in deciding on the extent of bone resection in malignant oral tumors. J Oral Maxillofac Surg 53, 768-770, doi:10.1016/0278-2391(95)90328-3 (1995).

21. Abd El-Hafez, Y. G. et al. Comparison of PET/CT and MRI for the detection of bone marrow invasion in patients with squamous cell carcinoma of the oral cavity. Oral Oncol 47, 288-295, doi:10.1016/j.oraloncology.2011.02.010 (2011).

22. Edge, S. B. \& Compton, C. C. The American Joint Committee on Cancer: the 7th edition of the AJCC cancer staging manual and the future of TNM. Ann Surg Oncol 17, 1471-1474, doi:10.1245/s10434010-0985-4 (2010). 